\title{
Filtering ionosphere parameters to detect trends linked to anthropogenic effects
}

Ana G Elias ${ }^{1,2}$

\begin{abstract}
The great concern about the global warming observed in the troposphere has generated a large interest in the study of long-term trends in the ionosphere since the early 1990s, which has now become a significant topic in global change investigations. Some research works link ionosphere trends to anthropogenic sources such as the increase in greenhouse gas concentration, and others to natural causes such as solar and geomagnetic activity long-term changes, and secular variations in the Earth's main magnetic field. In all the cases, in order to analyze ionospheric trends, solar activity effect must be filtered out first since around 90\% of ionosphere parameter variance is due to solar variations. The filtering process can generate 'spurious' trends in the filtered data series which may lead to erroneous conclusions. foF2 data series which include solar cycle 23 are analyzed in the present work in order to detect the effect of different filtering procedures on the determination of long-term trends. In particular, solar cycle 23 seems to have had an extreme ultraviolet (EUV) emission greater than that deduced from traditional solar EUV proxies during the maximum epoch and lower during the minimum epoch. When solar activity is filtered assessing the residuals of a linear regression between foF 2 and Rz, or between foF 2 and F10.7, this fact may bias trend values especially because it is at the end of the time series. The length of the period considered for trend assessment, the saturation and hysteresis effect of some ionosphere parameters, and the solar EUV proxy used are also considered in this study in order to quantify a possible spurious trend that may result as a by-product of a filtering process. Since trends expected as a consequence of anthropogenic effects are relatively small, these spurious effects may surely mask, or enhance, trends expected from anthropogenic origins.
\end{abstract}

Keywords: Long-term trends; Ionosphere; foF2; Solar EUV proxy; Greenhouse effect

\section{Background}

Long-term changes in ionospheric parameters were analyzed by many authors since the early 1990s, and, in general, after filtering the effects of solar activity, long-term variations, or trends, were reported. These trends were attributed to solar extreme ultraviolet (EUV) radiation changes (Adler et al. 1997; Yamazaki and Yumoto 2012), geomagnetic activity variations (Mikhailov and Marin 2001; Danilov 2002; Mikhailov 2001, 2006), the increase in greenhouse gas concentration (Bremer 1992, 1998; Upadhyay and Mahajan 1998; Ulich and Turunen 1997; Jarvis et al. 1998), and/or secular variations of the Earth's main magnetic field (Foppiano

Correspondence: anagelias@yahoo.com

${ }^{1}$ Consejo Nacional de Investigaciones Cientificas y Tecnicas, CONICET, Buenos Aires C1033AAJ, Argentina

${ }^{2}$ Departamento de Fisica, Universidad Nacional de Tucuman, Facultad de Ciencias Exactas y Tecnologia, Av. Independencia 1800, Tucuman 4000, Argentina et al. 1999; Elias and Adler 2006; Elias 2009; Yue et al. 2008; Cnossen and Richmond 2008, 2013; Cnossen et al. 2012).

The ionosphere varies greatly because of changes in the sources of ionization, that is, the solar EUV radiation, and changes in the neutral part of the upper atmosphere in which it is embedded which also depends on solar radiation, so that solar EUV radiation is the dominant influence on the ionosphere. In fact, solar EUV proxies such as Rz and F10.7 usually explain around 90\% of ionospheric parameters' variance once the annual variation has been filtered out from ionospheric data. This $90 \%$ value is obtained considering that for most ionospheric stations, the correlation coefficient between annual or 12-month running mean data of the critical frequency of the F2 layer, foF2 (or the E layer, foE) for example, and Rz (or F10.7) is around 0.95 . This means a variance explained of $0.95^{2}$, that is, 0.90 or $90 \%$. Long-term trends would represent

\section{Springer}


then at most the remaining $10 \%$. This makes necessary to filter ionospheric time series in order to enhance and make 'significantly' detectable these trends. Filtering procedures are based on the dependence of ionospheric parameters on solar EUV radiation which is almost linear as can be deduced from the well-known direct association of these parameters to solar EUV proxies such as $\mathrm{Rz}$ or F10.7. However, it should be noticed that for $\mathrm{Rz}>160$ and F10.7 $>200$, a saturation effect takes place which results in a nonlinear dependence (Liu et al. 2006, 2011). The risk of not considering this effect, which is significant at some stations but weak at others, is described in 'Saturation effect.'

The ionospheric parameter analyzed in the present work is the critical frequency of the F2 layer, foF2, which is a measure of the peak electron density, $\mathrm{NmF}$, in the ionosphere through

$$
\mathrm{NmF} 2=1.24 \times 10^{4}(\text { foF } 2)^{2} .
$$

Filtering is a standard mathematical operation which in our case is used to enhance features, as it is a longterm trend, otherwise not visibly apparent in the data. However, filtering can have unexpected consequences such as the introduction of spurious oscillations or a spurious trend (Chandler and Scott 2011). Special care is therefore required when making inferences from filtered time series.

foF2 data series which include solar cycle 23 are analyzed in the present work in order to detect the effect of different filtering procedures on the determination of long-term trends. The minimum of this solar cycle, between 2007 and 2009, is characterized by lower EUV solar radiation than during previous solar cycles. Wellknown solar activity proxies and also measurements give diverse results regarding the true percentage decrease (Solomon et al. 2013). The fact is that cycle 23 has had a EUV emission different than that deduced from traditional solar EUV proxies such as Rz and F10.7. Emmert et al. (2010) suggested that the long-term relationship between EUV irradiance and F10.7 has changed markedly since around 2006 with EUV levels decreasing more than expected from the F10.7 proxy. This result is also suggested by Chen et al. (2011). The opposite happened to the relationship between EUV and Rz during the solar cycle 23 maximum and declining phase where Rz underestimates EUV solar radiation (Lukianova and Murusla 2011).

When solar activity is filtered assessing the residuals of a linear regression between foF 2 and $\mathrm{Rz}$, or between foF2 and F10.7, which is a common filtering technique used in most of the publications that analyze ionosphere trends, the relationship between foF2 and the EUV proxy considered is expected to be the same over the whole period of analysis. If this is not the case, as happens during solar cycle 23, a spurious trend may be obtained. For example, a negative trend would result due to the overestimation of EUV radiation during the last minimum, or, considering the cycle 23 maximum, if $\mathrm{Rz}$ is being used as a solar EUV proxy, the underestimation of EUV would result in a spurious positive trend.

The length of the period considered for trend assessment, the saturation and hysteresis effect of some ionosphere parameters, and the solar EUV proxy used are also considered in this study in order to quantify a possible nonreal trend that may result as a by-product of a filtering process in comparison to the trends expected in the upper atmosphere as a consequence of anthropogenic effects.

The data analyzed and expected results due to the departure from linearity of foF2 vs EUV proxy are presented in 'Data analysis', followed by the 'Discussion and conclusions.'

\section{Methods}

Monthly median foF2 at 12 LT from three stations, which include solar cycle 23, were analyzed: Juliusruh $\left(54.6^{\circ} \mathrm{N}, 13.4^{\circ} \mathrm{E}\right)$, Slough $\left(51.5^{\circ} \mathrm{N}, 359.4^{\circ} \mathrm{E}\right)$, and Sodankyla $\left(67.3^{\circ} \mathrm{N}, 26.3^{\circ} \mathrm{E}\right)$.

As a first step, the seasonal variation, present in foF2 but not in solar activity, is filtered out applying a 12-month running mean to both foF 2 and the solar activity index considered. This process decreases the degrees of freedom by $1 / 12$. Another possibility would have been to analyze annual data, and in this case, the number of data would have been reduced in $1 / 12$, so both options are statistically equivalent.

The next step in order to finally assess trends is to filter out solar activity. One option is to apply an 11-year running mean to the time series, in which case the series are shortened in 11 years, and the degrees of freedom must be reduced again in $1 /(12 \times 11)$ assuming we are working with monthly data or $1 / 12$ if the series is annual. Since ionospheric time series are relatively short, this is not always a convenient procedure. Another option is to estimate the foF2 residuals from the regression between the experimental values and a modeled value representing foF2 values due only to solar activity effects, that is

$$
\text { foF2res }=\text { foF2exp }- \text { foF2mod }
$$

where foF2res is the foF2 residual, foF2exp is the experimental (or measured) foF2 data, and foF2mod is the modeled foF2 value in terms of solar activity which can be obtained through a model or through the well-known 
linear relationship between foF2 and a solar activity index such as Rz or F10.7, that is

$$
\text { foF } 2 \bmod =\mathrm{a} \mathrm{Rz}+\mathrm{b}
$$

where $a$ and $b$ are constants which can be determined with least squares. Finally, a regression of foF2res with time is adjusted with least squares so that

$$
\text { foF2res }=\alpha \mathrm{t}+\beta
$$

where $\alpha$ and $\beta$ are the regression coefficients and $\alpha$ is the trend we are interested in.

As can be noticed, $\alpha$ will depend on the steps previous to its calculation, and especially on the filtering process applied to the series involved.
There are at least five issues to consider regarding the latter filtering process: (1) saturation effect, (2) hysteresis effect, (3) nonlinearity, (4) the choice of the model or solar activity index to assess the modeled value, and (5) length of the period considered. Each of them is analyzed in the following subsections.

\section{Results and discussion}

\section{Saturation effect}

Saturation takes place in the case of some ionospheric stations, when Rz or F10.7 exceeds a certain value, beyond which the ionosphere seems not respond to a further increase in EUV radiation (Balan et al. 1994; Liu et al. 2003; Ma et al. 2009). It is linked to a breakdown of the linearity between foF2 and EUV (or solar index), as reported in
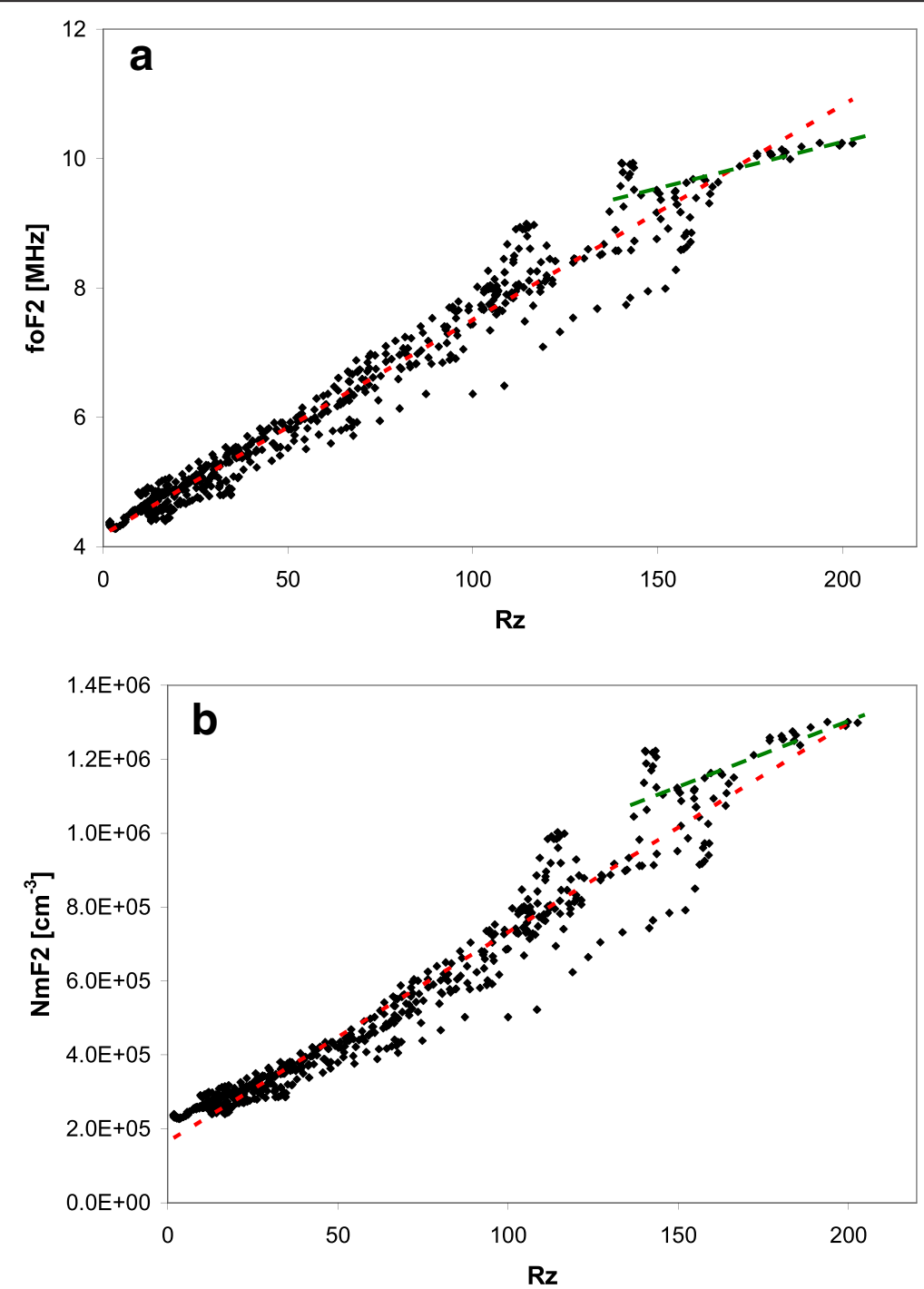

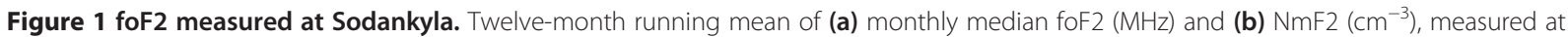
Sodankyla $\left(67.3^{\circ} \mathrm{N}, 26.3^{\circ} \mathrm{E}\right)$ at $12 \mathrm{LT}$, in terms of Rz. Least squares regression line (red dashed line). The green dashed line in (a) corresponds to the least squares regression line considering only years around the maximum of solar cycle 19. 
Liu et al. (2006, 2011), and the consequences may strongly influence the long-term trend reached.

Figure 1 shows as an example the case of Sodankyla. foF2 12-month running mean in terms of $\mathrm{Rz}$ increases with a certain rate until around $\mathrm{Rz}=160$, and beyond this value, a lower rate of foF2 increase can be noticed. This problem can be overcome in some cases using $\mathrm{foF}^{2}(\propto \mathrm{NmF} 2)$ instead of foF2, as can be noticed in Figure $1 \mathrm{~b}$. But since this is not always the case, another possibility is to exclude the period from the analysis.

This situation results in persistent negative residuals which will affect the trend value according to where this period of persistence is located within the whole period of analysis. If it is in the middle, it may not cause any spurious results, but if it is close to an extreme, it will depend if it is at the beginning, inducing a spurious positive trend, or at the end inducing a spurious negative trend.

In the case of Sodankyla, the period of saturation, that is, solar cycle 19, is at the beginning of the time series so it should be expected to be a positive or a less negative trend than the trend without considering this period. In fact, the trend from cycle 20 to cycle 23 results -0.010 and $-0.008 \mathrm{MHz} /$ year for the period from cycle 19 to cycle 23 . Although the difference is not statically significant, it results from the saturation effect.
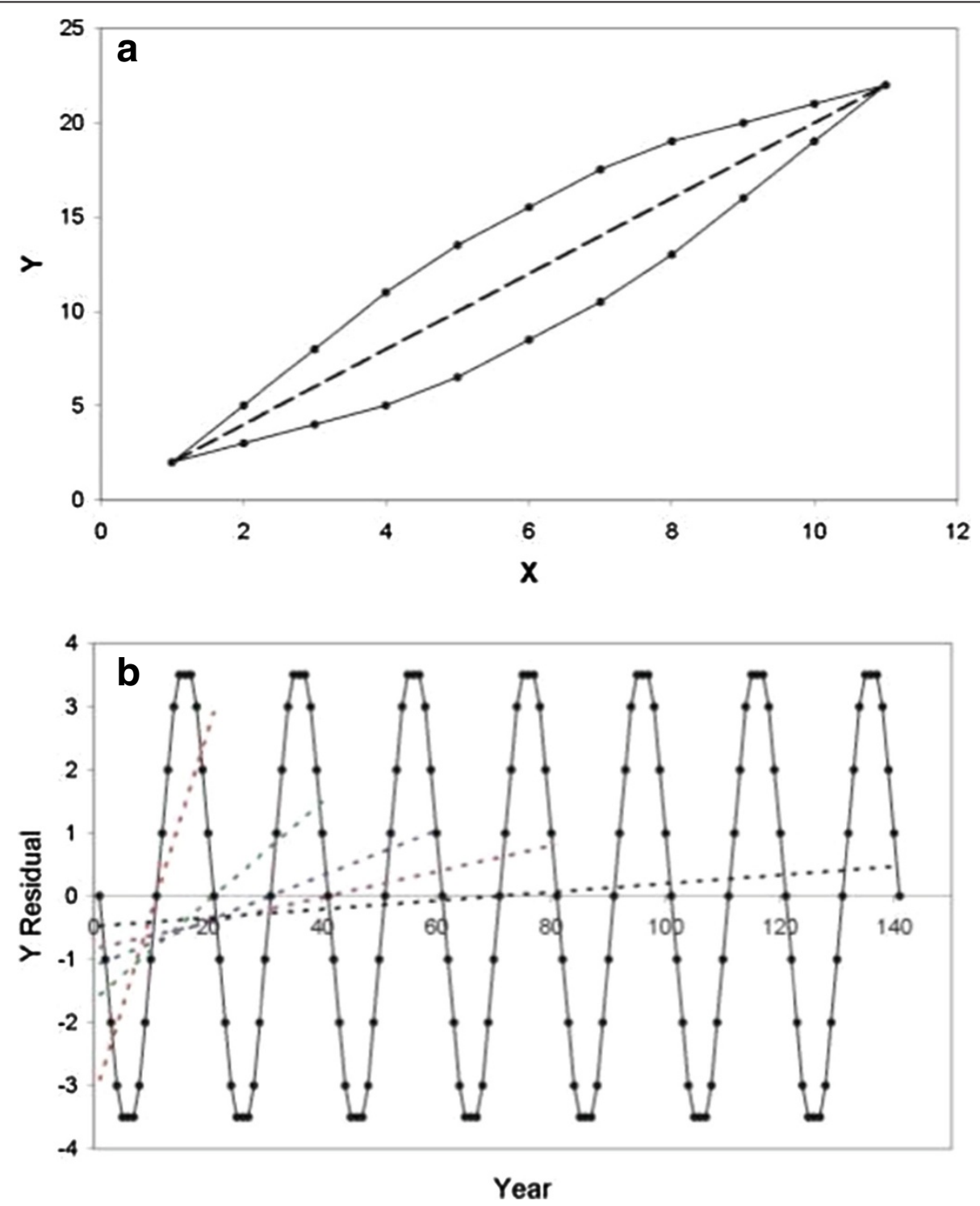

Figure 2 Schematic example of artificial hysteresis. (a) Artificial hysteresis of $y$ in terms of $x$ during a single cycle (solid line) and the 'ideal' linear function of $y$ in terms of $x$ during the same cycle (dashed line). (b) $y$ (during several cycles) after filtering $x$ using a linear filter (solid black line) and the linear trends obtained if only one cycle is used (red dashed line), two (green dashed line), three (blue dashed line), and so on (from Adler and Elias 2008). 


\section{Hysteresis effect}

The hysteresis effect refers to the fact that for the same value of solar activity level, foF2 may differ for the rising and falling parts of the 11-year solar cycle. The variation of foF2 then, over a complete solar cycle, displays a curve similar to the hysteresis variation of a magnetization cycle.

This phenomenon has been known for a long time (Naismith et al. 1961; Rao and Rao, 1969; Adler and Manzano 1995) and is attributed to the behavior of geomagnetic activity throughout the solar cycle (Mikhailov and Mikhailov 1995; Apostolov and Alberca 1995). The enhanced geomagnetic activity during the falling phase of the solar cycle would produce stronger F2 layer storm effects than during the rising phase.

If a time series presenting a hysteresis is filtered using a linear relationship between the variables, a spurious trend is obtained if the length of the time series does not include complete cycles. A schematic example of this is shown in Figure 2 which depicts an artificial hysteresis of $y$ in terms of $x$ and the trends obtained when different lengths are considered (from Adler and Elias 2008). This spurious trend can be offset as one considers more cycles in the trend estimation, as can be noticed from Figure 2b, or, as suggested by Danilov and Mikhailov (1999), using only the points around the maximum and minimum of a cycle.

Figure 3 shows foF2 measured at Slough using different colors for each complete solar cycle, and it can be clearly noticed that in addition to the hysteresis for each cycle, the ascending and descending slopes of each solar cycle phase are not the same for different cycles. Table 1 presents the trends obtained when the filtering is made for the period beginning in 1960 and ending in different
Table 1 foF2 trend values ( $\mathrm{MHz} /$ year) for Slough $\left(51.5^{\circ} \mathrm{N}\right.$, $\left.359.4^{\circ} \mathrm{E}\right)$

\begin{tabular}{lc}
\hline Period & Trend $(\mathbf{M H z} /$ year) \\
\hline 1960 to 1986 & -0.018 \\
1960 to 1989 & -0.016 \\
1960 to 1996 & -0.010 \\
1960 to 2000 & -0.009 \\
1960 to 2009 & -0.006 \\
\hline
\end{tabular}

foF2 trend values were estimated after filtering foF2 12-month running mean at 12 LT with F10.7 for the period beginning in 1960 and ending in 1986 (minimum between cycles 21 and 22), in 1989 (maximum of cycle 22), in 1996 (minimum between cycles 22 and 23), in 2000 (maximum of cycle 23), and in 2009 (minimum between cycles 23 and 24).

'half' cycles from solar cycle 22. That is, from 1960 until the first minimum of solar cycles 22, then from 1960 until the maximum of solar cycle 22 and so on until the last period from 1960 until the end of cycle 23. Cycles 22 and 23 were chosen because they present the stronger hysteresis. It can be noticed that trend absolute values decrease as each half cycle is added.

\section{Nonlinearity of foF2 vs solar EUV proxy}

One kind of nonlinearity between foF2 and solar EUV proxies is linked to the relationship between both variables. Liu and Chen (2009) and Liu et al. (2011) conclude that a quadratic regression, instead of a linear one, can describe the solar activity dependence fairly good and that higher-order regressions do not significantly improve the fitting. Chen et al. (2014), analyzing TEC-EUV relation under extremely low solar EUV, suggest a cubic fitting which takes into account the extreme ionosphere when solar EUV vanishes. As an example, Figure 4 shows

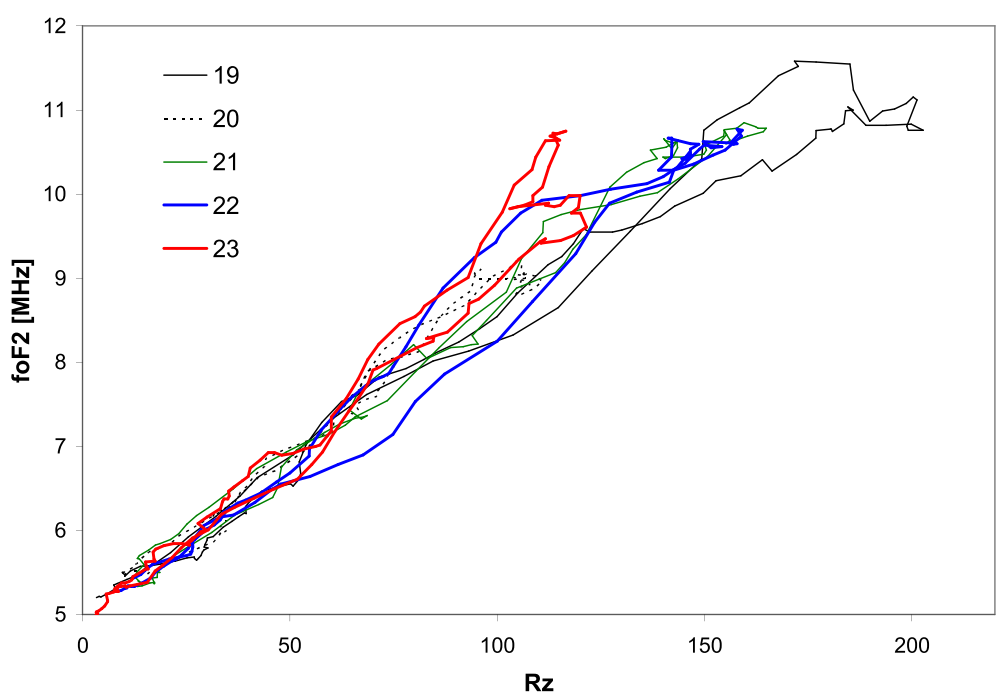

Figure 3 foF2 measured at Slough. Twelve-month running mean of monthly median foF2 ( $\mathrm{MHz})$ measured at Slough $\left(51.5^{\circ} \mathrm{N}, 359.4^{\circ} \mathrm{E}\right)$ in terms of Rz. foF 2 values have been joined consecutively in different colors for each solar cycle. 


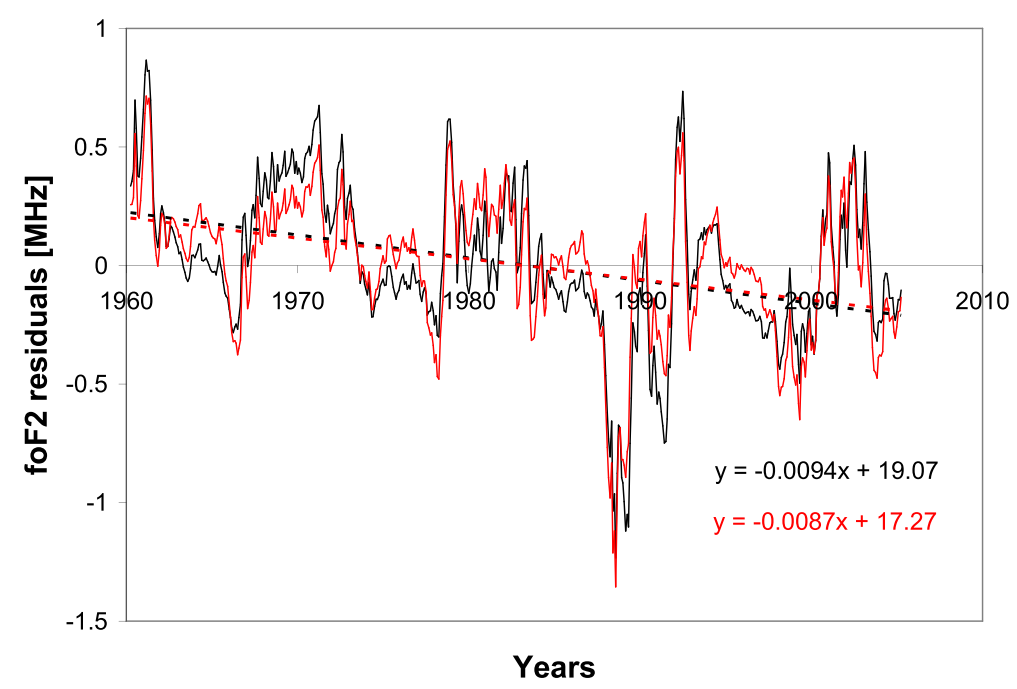

Figure 4 foF2 residuals for Juliusruh $\left(54.6^{\circ} \mathbf{N}, 13.4^{\circ} \mathrm{E}\right)$. foF2 residuals obtained considering foF2mod $=\mathrm{a} F 10.7^{2}+\mathrm{b} F 10.7+\mathrm{C}$ (red line) and considering foF2mod = a F10.7 + b (black line). Linear trends and their equation are also shown in the figure.

foF2 residuals obtained considering foF2 $\bmod =\mathrm{a} F 10.7^{2}+$ b F10.7 + c and also considering foF2mod $=$ a F10.7 + b, for the case of Juliusruh. The linear trends together with their equation are also shown in the figure. In the case of this station, the linear trend is almost the same for both cases, being $-0.009 \mathrm{MHz} /$ year.

Nonlinearity also refers to the possibility that the factor responsible for trends in the ionosphere, whichever may be, does not act with the same intensity along the solar cycle. In fact, Emmert et al. (2008) found that there is a solar cycle dependence of the long-term trends in thermospheric density (approximately -5 and $-2 \%$ per decade at solar minimum and maximum, respectively) and Mlynczak et al. (2010) observed that the infrared radiative cooling rates by $\mathrm{CO}_{2}$ and $\mathrm{NO}$ in Earth's thermosphere, which are the dominant radiative cooling mechanisms for the thermosphere, also vary with solar cycle activity level.

As an example, the trend of foF2 measured at Juliusruh has been assessed using the data set considering separately solar maximum and solar minimum epochs (see Figure 5). Periods around solar cycle minimum with $\mathrm{Rz}<25$ and around maximum with $\mathrm{Rz}>85$ were chosen for each epoch analysis. The trend values are $-4 \times 10^{-3} \mathrm{MHz} /$ year if only solar minimum periods are considered and $-5 \times 10^{-3} \mathrm{MHz} /$ year for periods of solar maximum. In this case, they are not statistically different, but the possibility of a statistically significant difference in trend estimation for other stations or as more solar cycles are included if $\mathrm{CO}_{2}$ and $\mathrm{NO}$ continue to increase should be kept in mind.

\section{EUV proxy}

The choice of the model or solar EUV proxy may affect the trend values as long as the model or proxy selected does not effectively reflect the real variance of foF2 due to the solar EUV radiation, which is the part one wants to filter before trend determination.

Figure 6 shows the residuals of foF2 measured at Slough, Juliusruh, and Sodankyla filtered using $\mathrm{Rz}$ and F10.7 as solar EUV proxies. It can be noticed in the three cases that $\mathrm{Rz}$ underestimates EUV during solar cycle 23 maximum (around year 2002) and that F10.7 overestimates EUV during solar cycle 23 minimum (around years 2008 and 2009). Trend values for the 1960 to 2009 period, listed in Table 2, are different, and for two of the three stations, even the sign differs. All trend values are significantly different from zero at a $95 \%$ confidence level, except in the case of Sodankyla filtered with Rz. The significance was assessed calculating the statistic $t$ as $\alpha / \sigma$ :

$$
t=\frac{\alpha}{\sigma}=\frac{\alpha}{\frac{\alpha}{\sqrt{n-2}} \sqrt{\frac{1}{r^{2}}-1}}=r \frac{\sqrt{n-2}}{\sqrt{1-r^{2}}}
$$

where $\sigma$ is the standard deviation of trend $\alpha$ and $r$ is the correlation coefficient of the regression between foF2res and time. The statistic $t$ value obtained in each case is tested against the Student's $t$ value of 1.96 which corresponds to 48 degrees of freedom (50, which results from the 50 years of monthly data divided by 12 due to the 12 month running mean, minus 2) and 0.025 significance level. As can be deduced from Table 2, in all cases except Sodankyla filtered with $\mathrm{Rz}, t$ results greater than 1.96.

\section{Length of period}

The length of the period considered is related to the stability of the trend value in terms of the time series 

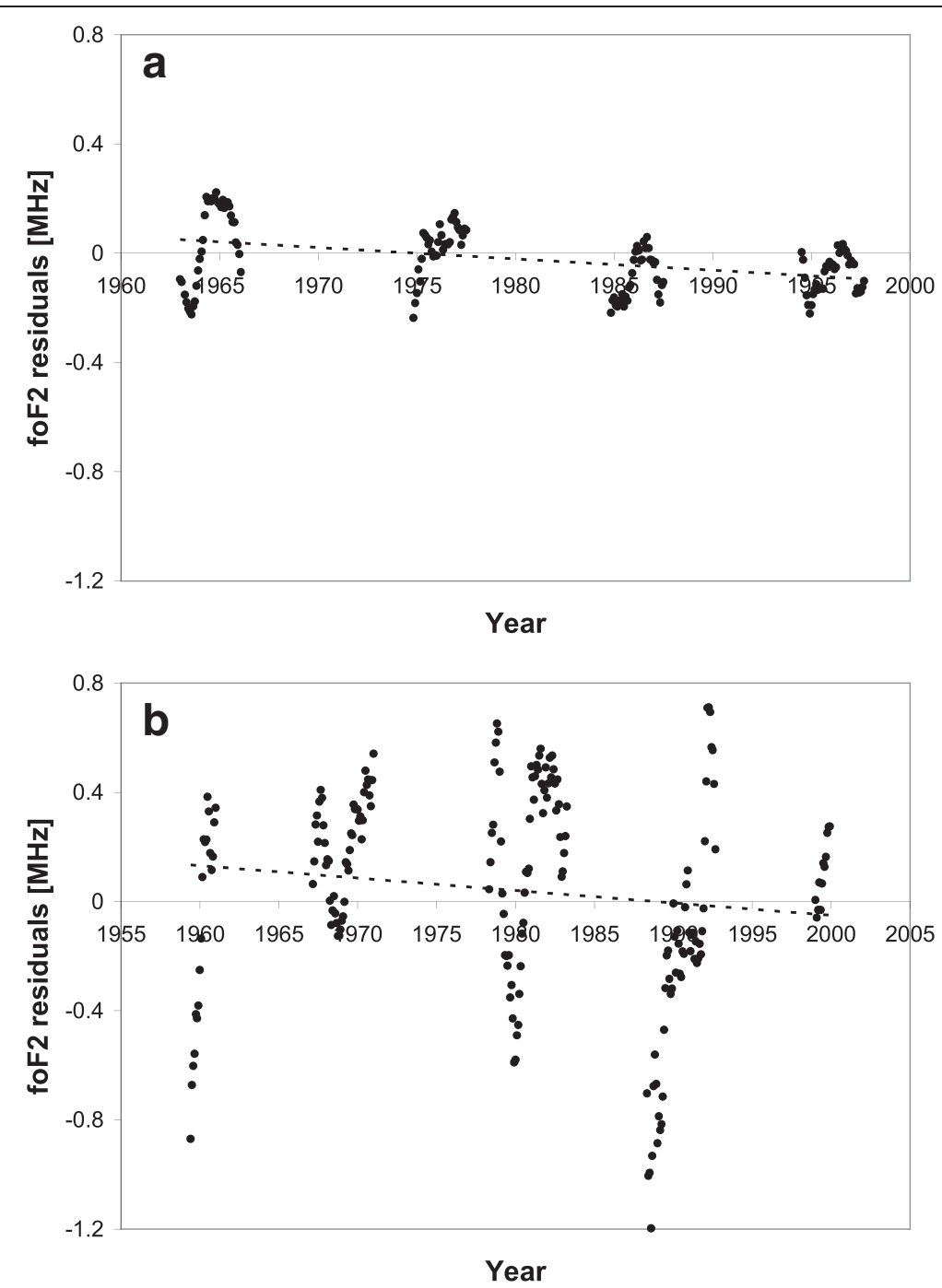

Figure 5 Trend of foF2 measured at Juliusruh. foF2 residuals obtained using only years around solar activity (a) minimum periods and (b) maximum periods, filtering solar activity with F10.7. Linear trends (dashed line) are $-4 \times 10^{-3} \mathrm{MHz} / \mathrm{year}$ in (a) and $-5 \times 10^{-3} \mathrm{MHz} / \mathrm{year}$ in (b).

length. Mielich and Bremer (2013) discuss in detail this point for hmF2 and foF2 data, showing that trends for increasing data intervals present more stable variations, and suggest that the derived mean hmF2 and foF2 trends are more reliable for longer data intervals.

Figure 7 shows the foF2 trend estimated first for the 1960 to 1980 period and since then adding 1 year but beginning always in 1960 . The $95 \%$ confidence level is also shown in the figure. For the period since 1960 until 1990 and 2000, the trend seems to be stabilized and negative in agreement with the decreasing trend in foF2 expected from a cooling in the thermosphere. However, when solar cycle 23 begins to be included in the trend estimation, the trend value becomes less negative or even positive when $\mathrm{Rz}$ instead of F10.7 is used to filter out solar activity effect.
Figure 8 shows the running foF2 trend using a window of 20 years. That is, a 20 -year period is considered in the trend estimation. Here, it is clear that when solar cycle 23 is included in trend estimation for a relatively short period (which is 20 years spanning only two solar cycles), a positive trend may be obtained as a result of the persistent positive residuals obtained in the filtering process due to EUV proxies underestimating solar EUV radiation during this period.

\section{Conclusions}

One of the main foci of climate science is to determine the extent to which human activities are altering the planetary energy balance through the emission of greenhouse gases and pollutants. The ionosphere is one component affected by greenhouse gases. However, this anthropogenic effect 

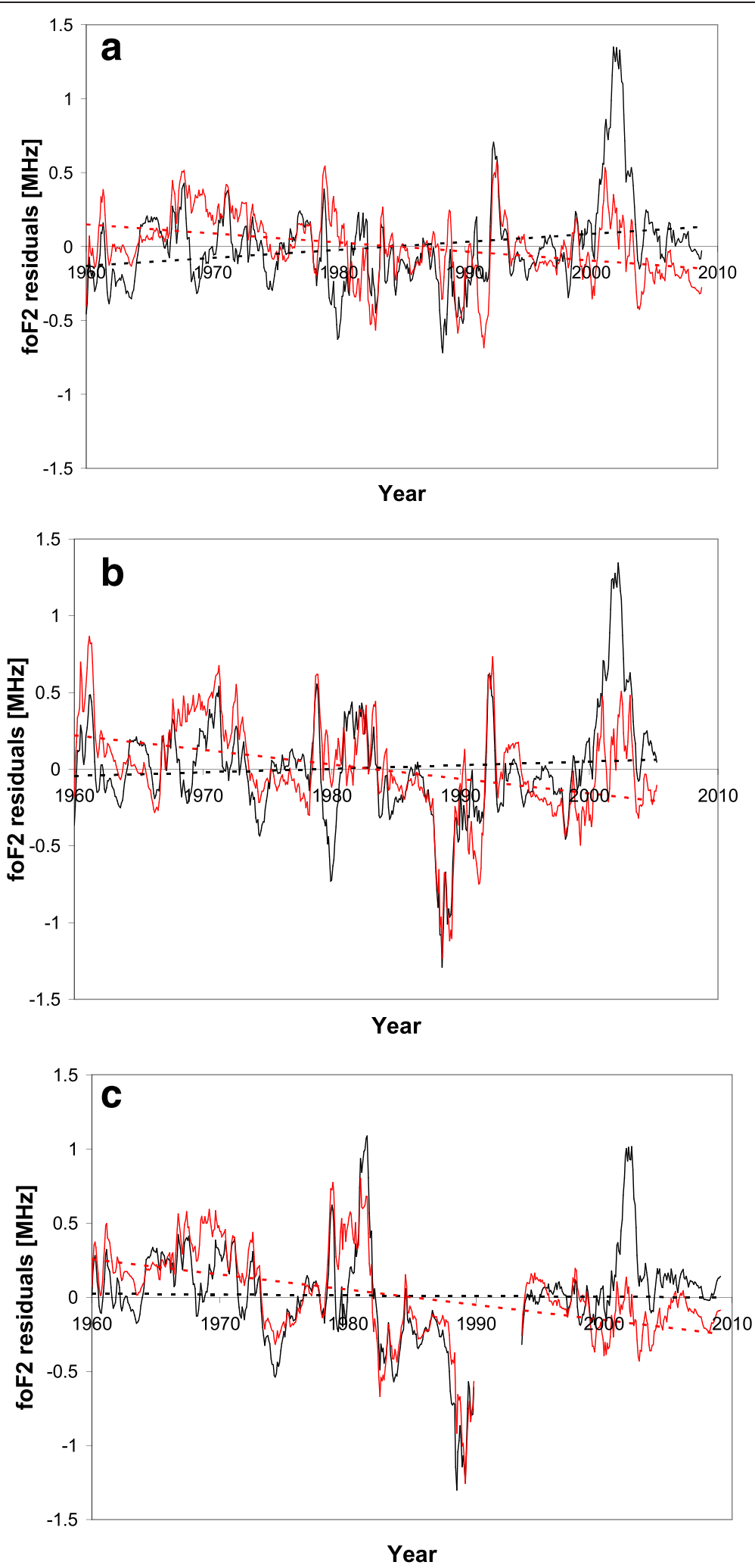

Figure 6 foF2 residuals. foF2 residuals ( $\mathrm{MHz}$ ) estimated using Rz (black line) and F10.7 (red line) as solar EUV radiation proxies for (a) Slough, (b) Juliusruh, and (c) Sodankyla. Linear trends (dashed lines) are listed in Table 2. 
Table 2 foF2 trend values (MHz/year) estimated after filtering foF2 12-month running mean at 12 LT

\begin{tabular}{lcccc}
\hline Station & Lat. & Long. & foF2 trend (filtered with $\mathbf{~ z z}) \times \mathbf{1 0}^{-\mathbf{3}} \mathbf{~ M H z} /$ year & foF2 trend (filtered with F10.7) $\times \mathbf{1 0}^{\mathbf{- 3}} \mathbf{~ M H z} / \mathbf{y e a r}$ \\
\hline Slough & $51.5^{\circ} \mathrm{N}$ & $359.4^{\circ} \mathrm{E}$ & $5 \pm 2$ & $-6 \pm 1$ \\
Juliusruh & $54.6^{\circ} \mathrm{N}$ & $13.4^{\circ} \mathrm{E}$ & $2 \pm 2$ & $-9 \pm 2$ \\
Sodankyla & $67.3^{\circ} \mathrm{N}$ & $26.3^{\circ} \mathrm{E}$ & $0 \pm 2$ & $-10 \pm 2$
\end{tabular}

Trend values were calculated with Rz (fourth column) and with F10.7 (fifth column) as solar EUV radiation proxies, for the 1960 to 2009 period. The error is estimated as twice the standard deviation.

is so small that in order to detect it, all other variability must be filtered out first.

In this paper, several sources which may hinder the filtering process have been analyzed. Filtering is a critical step toward trend estimation since a bad filtering leads inevitably to a bad result unless there is compensation, which occurs randomly. Lastovicka et al. (2006), having noticed that results on long-term trends in foF 2 and their interpretation did not reveal a consistent pattern, carried out a joint analysis foF2 trend estimation. One problem in fact is the filtering process selected by each author which gives different results in some cases for the same foF2 time series analyzed.

Recently, Mielich and Bremer (2013) analyzed more than 100 stations in order to detect the best index to filter solar activity from foF2 and hmF2. They conclude that

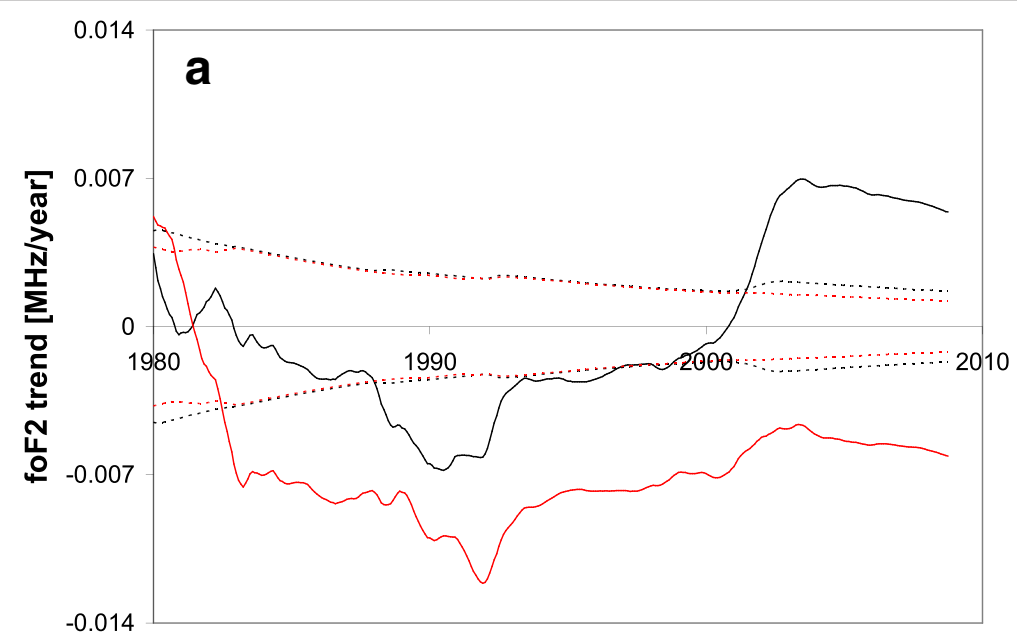

Final year starting at 1960

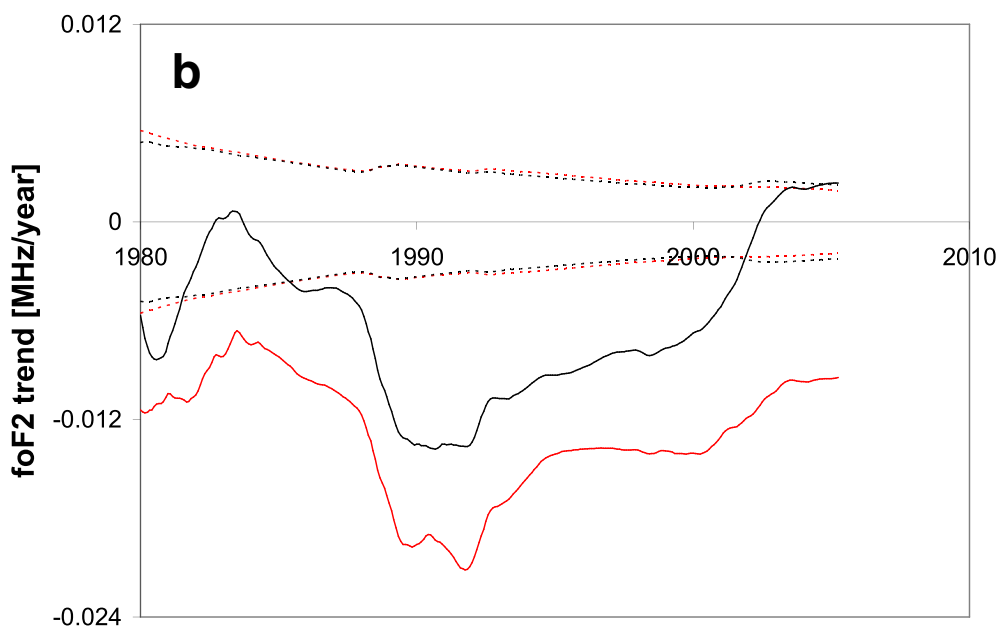

Final year starting at 1960

Figure 7 foF2 trend estimated for the 1960 to 1980 period. foF2 trend (MHz/year) estimated for periods beginning in 1960 for (a) Slough and (b) Juliusruh. Trend values are assigned to the last year of the period of trend estimation. The $95 \%$ confidence level (dashed lines) using Rz (black line) and F10.7 (red line) as solar EUV radiation proxies is shown. 


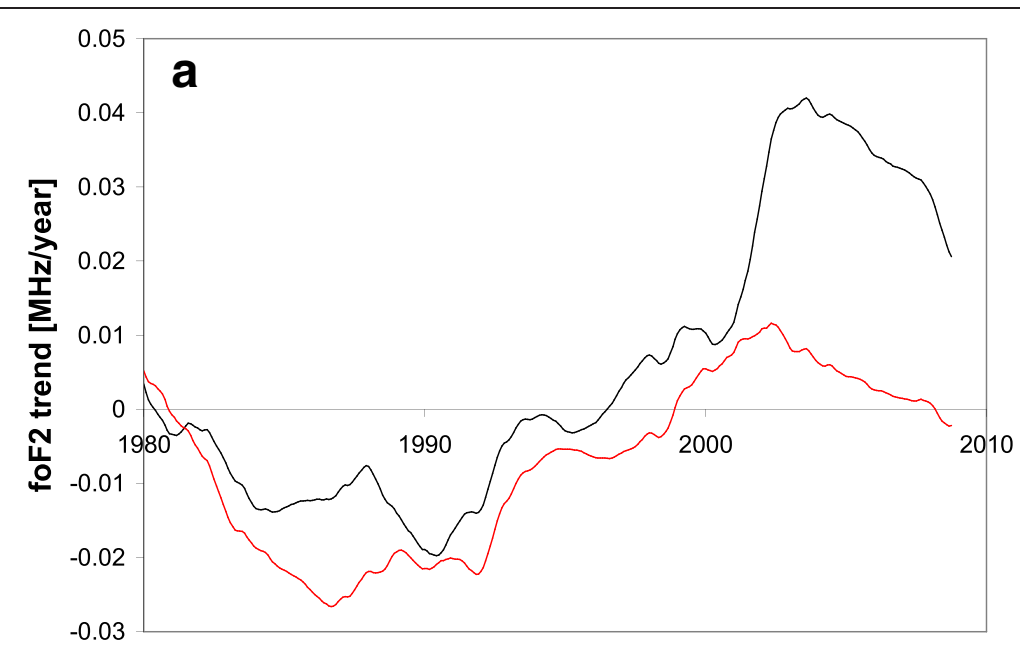

Final year (20-year period)

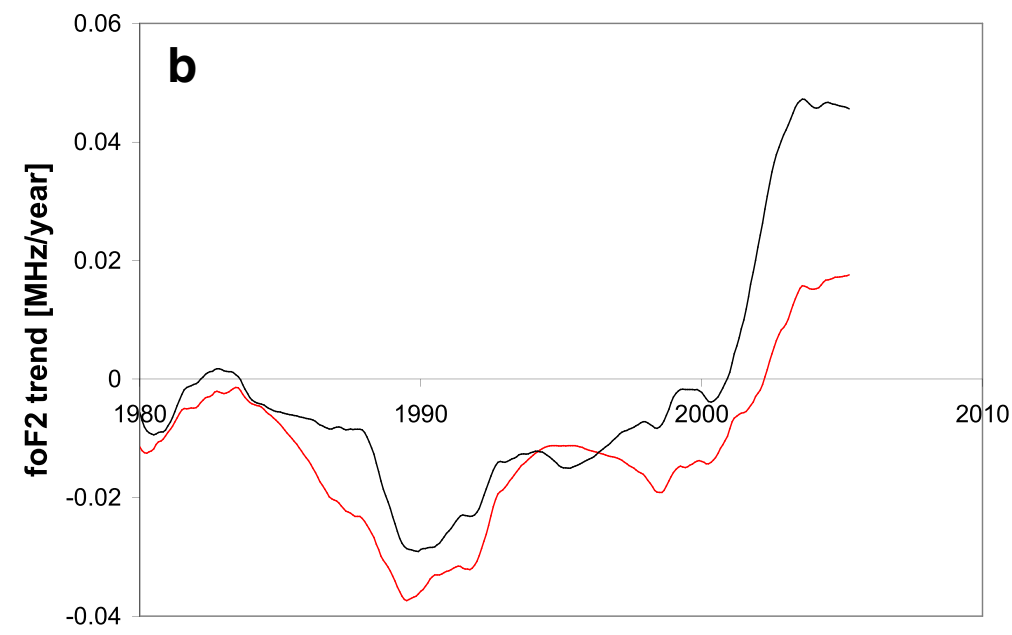

Final year (20-year period)

Figure 8 Running foF2 trend ( $\mathbf{M H z} /$ year) using a window of $\mathbf{2 0}$ years for (a) Slough and (b) Juliusruh. Trend values are assigned to the last year of the 20-year period of trend estimation.

F10.7 is a better index for the description of the solar activity than Rz. Damboldt and Suessmann (2012) filtered the solar cycle influence using a Comité Consultatif International des Radiocommunications (CCIR) ionospheric prediction model, which uses $\mathrm{Rz}$ as a solar EUV proxy. They obtained a trend reversal in hmF2 in 1963 to 1964 with negative trends from 1942 to 1963 and positive trends from 1964 to 2005 , which is in contrast to the results reported in most other publications of ionospheric long-term trends. A plausible cause of this would be that CCIR uses $\mathrm{Rz}$ as solar activity index.

According to the results presented here, three recommendations for trend assessments which can be easily handled are suggested. One is not to include periods with F10.7 > 200, or at least test that the residuals for these periods are not systematically negative. The other two were already made by Mielich and Bremer (2013): use F10.7 instead of Rz, since it follows more closely EUV solar flux, and the length of period considered should be long enough so as to obtain a stable trend since at least the last 4 to 5 years of the data series considered (almost half a solar cycle).

Why is important to do a correct filtering of ionospheric (or atmospheric in general) parameters? We live in the Earth and we want to understand and predict the atmosphere behavior which is essential for human life. A correct filtering would guarantee a good result from which right conclusions regarding variations of small amplitudes such as long-term trends are extracted.

Regarding ionosphere, at least the five mentioned issues regarding filtering process should be taken into account in order to be sure about trend value results. 


\section{Competing interests}

The author declares that she has no competing interests.

\section{Acknowledgements}

I would like to thank two anonymous reviewers for their helpful comments and to the Nagoya CAWSES-II Symposium organizers for the important financial support they gave me. This research was performed under project Prestamo BID - PICT 2011-1008.

Received: 8 April 2014 Accepted: 22 August 2014

Published: 10 September 2014

\section{References}

Adler NO, Manzano JR (1995) Solar cycle hysteresis on F-region electron concentration peak heights over Tucuman. Adv Space Res 15:83-88

Adler NO, Elias AG, Manzano JR (1997) Solar cycle length variation: its relation with ionospheric parameters. J Atmos Solar Terr Phys 59:159-162

Adler NO, Elias AG (2008) Latitudinal variation of foF2 hysteresis of solar cycles 20, 21 and 22. Ann Geophys 26:1269-1273

Apostolov EM, Alberca LF (1995) foF2 hysteresis variations and the semi-annual geomagnetic wave. J Atmos Terr Phys 57:755-757

Balan N, Bailey GJ, Jenkins B, Rao PB, Moffet RJ (1994) Variations of ionospheric ionization and related solar fluxes during an intense solar cycle. J Geophys Res 99:2243-2253

Bremer J (1992) lonospheric trends in mid-latitudes as a possible indicator of the atmospheric greenhouse effect. J Atmos Terr Phys 54:1505-1511

Bremer J (1998) Trends in the ionospheric E and F regions over Europe. Ann Geophys 16:986-996

Chandler RE, Scott EM (2011) Statistical methods for trend detection and analysis in the environmental sciences. John Wiley \& Sons, London

Chen Y, Liu L, Wan W (2011) Does the F10.7 index correctly describe solar EUV flux during the deep solar minimum of 2007-2009? J Geophys Res 116:A04304

Chen Y, Liu L, Le H, Wan W (2014) How does ionospheric TEC vary if solar EUV irradiance continuously decreases? Earth, Planets and Space 66:52

Cnossen I, Richmond AD (2008) Modelling the effects of changes in the Earth's magnetic field from 1957 to 1997 on the ionospheric hmF2 and foF2 parameters. J Atmos Solar Terr Phys 70:1512-1524

Cnossen I, Richmond AD, Wiltberger M (2012) The dependence of the coupled magnetosphere-ionosphere-thermosphere system on the Earth's magnetic dipole moment. J Geophys Res 117:A05302, doi:10.1029/2012JA017555

Cnossen I, Richmond AD (2013) Changes in the Earth's magnetic field over the past century: effects on the ionosphere-thermosphere system and solar quiet (Sq) magnetic variation. J Geophys Res 118:849-858, doi:10.1029/ 2012JA018447

Damboldt T, Suessmann P (2012) Statistic of long-term ionospheric measurements. Adv Radio Sci 10:255-258

Danilov AD, Mikhailov AV (1999) Spatial and seasonal variations of the foF2 long-term trends. Ann Geophys 17:1239-1243

Danilov AD (2002) Overview of the trends in the ionospheric E and F2 regions. Phys Chem Earth 27:579-588

Elias AG, Adler NO (2006) Earth magnetic field and geomagnetic activity effects on long term trends in the F2 layer at mid-high latitudes. J Atmos Solar Terr Phys 68:1871-1878

Elias AG (2009) Trends in the F2 ionospheric layer due to long-term variations in the Earth's magnetic field. J Atmos Solar Terr Phys 71:1602-1609

Emmert JT, Picone JM, Meier RR (2008) Thermospheric global average density trends, 1967-2007, derived from orbits of 5000 near-Earth objects. Geophys Res Lett 35, doi:10.1029/2007GL032809

Emmert JT, Lean JL, Picone JM (2010) Record-low thermospheric density during the 2008 solar minimum. Geophys Res Lett 37, doi:10.1029/2010GL043671

Foppiano AJ, Cid L, Jara V (1999) lonospheric long-term trends for South American mid-latitudes. J Atmos Solar Terr Phys 61:717-723

Jarvis MJ, Jenkins B, Rodgers GA (1998) Southern hemisphere observations of a long-term decrease in $\mathrm{F}$ region altitude and thermospheric wind providing possible evidence for global thermospheric cooling. J Geophys Res 103:20774-20787

Lastovicka J, Mikhailov AV, Ulich T, Bremer J, Elias AG, Ortiz de Adler N, Jara V, Abarca del Rio R, Foppiano AJ, Ovalle AE, Danilov D (2006) Long-term trends in foF2: a comparison of various methods. J Atmos Solar Terr Phys 68:1854-1870
Liu JY, Chen YI, Lin JS (2003) Statistical investigation of the saturation effect in the ionospheric foF2 versus sunspot, solar radio noise, and solar EUV radiation. J Geophys Res 108(A2):1067, doi:10.1029/2001JA007543

Liu L, Wan W, Ning B, Pirog OM, Kurkin VI (2006) Solar activity variations of the ionospheric peak electron density. J Geophys Res 111, A08304, doi:10.1029/ 2006JA011598

Liu L, Chen Y (2009) Statistical analysis of solar activity variations of total electron content derived at Jet Propulsion Laboratory from GPS observations. J Geophys Res 114:A10311, doi:10.1029/2009JA014533

Liu L, Wan W, Chen Y, Le H (2011) Solar activity effects of the ionosphere: a brief review. Chinese Sci Bull 56:1202-1211, doi:10.1007/s11434-010-4226-9

Lukianova R, Murusla K (2011) Changed relation between sunspot numbers, solar UV/EUV radiation and TSI during the declining phase of solar cycle 23. J Atmos Solar Terr Phys 73:235-240

Ma R, Xu J, Wang W, Yuan W (2009) Seasonal and latitudinal differences of the saturation effect between ionospheric NmF2 and solar activity indices. J Geophys Res 114:A10303, doi:10.1029/2009JA014353

Mielich J, Bremer J (2013) Long-term trends in the ionospheric F2 region with different solar activity indices. Ann Geophys 31:291-303

Mlynczak MG, Hunt LA, Marshall BT, Martin-Torres FJ, Mertens CJ, Russell JM III, Remsberg EE, López-Puertas M, Picard R, Winick J, Wintersteiner P, Thompson $\mathrm{RE}$, Gordley LL (2010) Observations of infrared radiative cooling in the thermosphere on daily to multiyear timescales from the TIMED/SABER instrument. J Geophys Res 115:A03309, doi:10.1029/2009JA014713

Mikhailov AV, Mikhailov W (1995) Solar cycle variations of annual mean noon foF2. Adv Space Res 15:79-82

Mikhailov AV, Marin D (2001) An interpretation of the foF2 and hmF2 long-term trends in the framework of the geomagnetic control concept. Ann Geophys 19:733-748

Mikhailov AV (2001) The geomagnetic control concept of the F2-layer parameter long-term trends. Phys Chem Earth 27:595-606

Mikhailov AV (2006) Trends in the ionospheric E-region. Phys Chem Earth 31:22-33

Naismith R, Bevan HC, Smith PA (1961) A long term variation in the relationship of sunspot numbers to E-region character figures. J Atmos Terr Phys 21:167-173

Rao MSVG, Rao RS (1969) The hysteresis variation in F2-layer parameters. J Atmos Terr Phys 31:1119-1125

Solomon SC, Qian L, Burns AG (2013) The anomalous ionosphere between solar cycles 23 and 24. J Geophys Res 118:6524-6535, doi:10.1002/jgra.50561

Upadhyay HO, Mahajan KK (1998) Atmospheric greenhouse effect and ionospheric trends. Geophys Res Lett 25:3375-3378

Ulich T, Turunen E (1997) Evidence for long-term cooling of the upper atmosphere in ionosonde data. Geophys Res Lett 24:1103-1106

Yamazaki Y, Yumoto K (2012) Long-term behavior of annual and semi-annual Sq variations. Earth Planets Space 64:417-423

Yue X, Liu L, Wan W, Wei Y, Ren Z (2008) Modeling the effects of secular variation of geomagnetic field orientation on the ionospheric long term trend over the past century. J Geophys Res 113, A10301, doi:10.1029/2007JAO12995

doi:10.1186/1880-5981-66-113

Cite this article as: Elias: Filtering ionosphere parameters to detect trends linked to anthropogenic effects. Earth, Planets and Space $201466: 113$

\section{Submit your manuscript to a SpringerOpen ${ }^{\circ}$ journal and benefit from:}

- Convenient online submission

- Rigorous peer review

- Immediate publication on acceptance

- Open access: articles freely available online

- High visibility within the field

- Retaining the copyright to your article

Submit your next manuscript at $>$ springeropen.com 